\title{
An Optimal Peer Group Selection Strategy for Multiples-Based Modeling in the South African Equity Market
}

\author{
WS Nel*, NJ le Roux \\ University of Stellenbosch, Matieland, South Africa \\ *snel@sun.ac.za
}

\begin{abstract}
Although peer group selection is a key consideration when performing multiples-based valuations, there is a lack of theoretical guidance on an optimal peer group selection strategy in emerging markets. Principal Component Analysis-based biplots and correlation monoplots are used to assess the valuation performance of multiples whose peer groups are based on either industry classification or valuation fundamentals. The evidence suggests that multiples whose peer groups are based on valuation fundamentals outperform multiples whose peer groups are based on industry classifications, with a combination of valuation fundamentals $\mathrm{Rg}$ and $\mathrm{RoE}$ emerging as the optimal peer group variable. The evidence suggests that an optimal choice of peer group variable could secure an increase in valuation precision of as much as $41.77 \%$.
\end{abstract}

Keywords: Peer group selection, multiples, emerging markets, valuation precision, valuation

\section{Introduction}

Multiples are arguably the most popular valuation approach used in practice (Bhojraj and Lee, 2002; Asquith, Mikhail and Au, 2005; Damodaran, 2006b; Roosenboom, 2007; Minjina, 2008; Dellinger, 2010; PwC, 2012). Accordingly, one would expect the construction of multiples to be underpinned by a wellresearched body of evidence. However, the emerging market literature, in particular, offers surprisingly little empirical guidance in this regard. Multiples are constructed by scaling market price variables with matching value drivers (Schreiner and Spremann, 2007; Damodaran, 2009). Analysts typically start by identifying the target company's peer group, i.e. a group of companies with similar risk and growth profiles to that of the target company. A peer group multiple is subsequently estimated for the company that is to be valued, i.e. the target company, and then multiplied by the target company's value driver to estimate the value of the target company or its equity. The basic assumption underlying multiples-based modeling is that similar companies are valued similarly. Therefore, a peer group of companies should emanate a certain degree of similarity to the target company, in terms of key factors such as size, growth prospects and profitability (Ernst and Häcker, 2012). The greater the degree of similarity between the peer group of companies and the target company, the more accurate the valuation will be. The latter is the theoretical underpinning of a multiples-based approach to company valuations. If there is a lack of comparability between the peer group of companies and the target company, a multiples-based approach seems nonsensical.

The current literature offers two approaches to peer group selection. The first approach categorizes companies together in peer groups based on their industry classification. Internationally recognized classification systems, such as the Standard Industry Classification (SIC) system or the Global Industry Classification Standard (GICS) system, for example, could be used to group similar companies together to form a peer group to the target company (Goedhart, Koller and Wessels, 2010). Categorizing companies together in various industry classifications helps explain cross-sectional variations in key fundamental valuation variables, such as multiples and historic and future growth rates. However, companies comprising a peer group based on the same SIC code may still vary substantially in terms of their business models and sales structures, for example. Consequently, an alternative approach to peer group selection would be to categorize companies together based on valuation fundamentals. However, empirical evidence regarding these two approaches to peer group selection in emerging markets is limited. The relative valuation performance of multiples whose peer group selection was based on each of these two schools of thought has not yet been pitted against each other in an emerging market context. Consequently, the focus of this paper is on investigating an optimal basis for the compilation of a target company's peer group. 
The primary objective of this study is to establish the relative valuation performances of multiples whose peer groups are based on each of two major schools of thought on peer group selection, namely the industry classification and the valuation fundamentalists. To this end, the valuation performances of three different types of peer group variables (PGVs), namely industry classifications, individual valuation fundamentals and combined valuation fundamentals, are compared in the South African market. The secondary aim is to establish which of the ten PGVs, if any, offers the greatest degree of valuation precision. The third aim is to measure the magnitude of the potential improvement in valuation precision that an optimal peer group selection strategy may offer over other, sub-optimal peer group selection strategies. Section 2 offers a review of the literature, followed by the data selection process in Section 3 and the research methodology in Section 4. The empirical findings are offered in Section 5, after which concluding remarks are presented in Section 6.

\section{Literature Review}

Peer group selection is a key consideration when performing multiples-based valuations (Fuller and Kerr, 1981; Lang and Stulz, 1992; Fenn and Cole, 1994; Eberhart, 2001; Bhojraj and Lee, 2002; Nel, Bruwer and Le Roux, 2013a, b). Despite the lack of theoretical guidance on peer group selection in emerging markets, there are two schools of thought in this regard (Bhojraj and Lee, 2002). The first school of thought argues that peer group selection should be based on industry classification (Alford, 1992; Damodaran, 2006a; Nel et al., 2013a, b). The premise of the proponents of industry classification as a basis for peer group selection is that companies operating in similar industries will have similar profitability, growth and risk profiles. The second school of thought argues that peer group selection should be based on companies with similar valuation fundamentals (Dittmann and Weiner, 2005; Goedhart, Koller and Wessels, 2005). The premise of the proponents of valuation fundamentals as a basis for peer group selection is that companies with similarly sized economic variables will have similar profitability, growth and risk profiles. The search for the most effective basis for peer group selection is not a new phenomenon. Evidence from the developed market literature suggests that the valuation precision of multiples increases when their peer groups are based on more narrowly defined industry classifications vis-à-vis more widely defined industry classifications (Alford, 1992; Damodaran, 2006a; Schreiner, 2007; Henschke and Homburg, 2009). The obvious conclusion drawn from these results is that a more narrowly defined peer group contains more homogeneous companies vis-à-vis a more widely defined peer group, which will contain more heterogeneous companies.

Initial research findings published in the developed market literature by Alford (1992) suggested that peer group selection based on valuation fundamentals failed to result in an increase in valuation precision vis-à-vis peer group selection based on industry classification. However, subsequent studies by Henschke and Homburg (2009); Dittmann and Weiner (2005); Goedhart et al. (2005); Herrmann and Richter (2003); Bhojraj and Lee (2002) and Cheng and McNamara (2000) found that peer group selection based on valuation fundamentals offered substantial improvements in valuation precision over peer group selection based on industry classifications. Although the evidence, therefore, suggests that multiples whose peer group selection is based on valuation fundamentals offers superior explanatory power vis-àvis multiples whose peer group selection is based on industry classification, these findings emanate from studies that focused on the relatively deeply traded and liquid markets of developed countries.

Empirical evidence regarding effective peer group selection methods in emerging markets is limited. The literature offers two studies that focussed on peer group selection methodology in South Africa, one of the emerging BRICS (Brazil, Russia, India, China and South Africa) countries. The initial findings of Nel et al. (2013a) suggested that multiples whose peer groups are based on narrower industry classifications produced more accurate valuations compared to multiples whose peer groups were based on wider industry classifications. In a follow-up on their original work, Nel, Bruwer and Le Roux (2014a) also tested the valuation precision of multiples whose peer group selection was based on seven valuation fundamentals and found that there is a substantial differential in valuation precision, depending on the choice of valuation fundamental. The emerging market evidence suggests that the valuation precision of multiples increases when their peer groups are based on a combination of valuation fundamentals vis-àvis single factor valuation fundamentals (Nel et al., 2014a). However, the relative valuation performance of multiples whose peer group selection was based on each of two schools of thought has not yet been pitted against each other. The question, however, is why one would expect the results to be any different to that of the developed market literature? 
Analysts encounter various challenges when transacting in emerging markets, including currency volatility, unreliable market measures and accounting differences (Damodaran, 2009). Other obstacles in emerging markets relate to corruption, lack of infrastructure, trade barriers, an unproductive labor force and skills shortages (IMF, 2012). A constraint specific to emerging markets, especially when investigating the basis for an optimal peer group selection strategy, is data limitations (Omran, 2003; Sehgal and Pandey, 2009). Based on the number of companies listed, the JSE Securities Exchange (JSE) is between 10$15 \%$ the size of the National Association of Securities Dealers Automated Quotations (NASDAQ), for example (Profile, 2011; World Federation of Exchanges (WFE), 2013). Given the focus of this study, the lack of depth within the JSE places a further strain on the adoption of an optimal peer group selection strategy for multiples-based valuation purposes. Accordingly, one might be inclined to expect that evidence obtained from emerging markets may differ from that obtained from the developed markets. It is hoped that this study will indicate whether this is, indeed, the case and to what extent.

Data Selection: The following variables were extracted from the McGregor BFA database, one of the leading data houses in South Africa (PwC, 2012): Market Capitalization (MCap), Shares in issue, Gross Profit (GP), Earnings Before Interest, Tax, Depreciation and Amortization (EBITDA), Earnings Before Interest and Tax (EBIT), Profit After Tax (PAT), Profit Before Tax (PBT), Headline Earnings (HE), Total Assets (TA), Invested Capital (IC), Book Value of Equity (BVE), Revenue (R), Cash generated by Operations (CgbO), Increase/decrease in working capital, Net Cash Inflow from Operating Activities (NCIfOA), Net Cash Inflow from Investment Activities (NCIfIA), Ordinary Dividends (OD), Taxation paid, Fixed assets acquired, Net interest paid/received, Secondary tax on entities, Capital profits/losses on financial assets, Normal taxation included in extraordinary items, Total profit of an extraordinary nature, Industry (IND), Super Sector (SUP), Sector (SEC), Subsector (SUB), Company name (CPY), Ticker symbol (TIC) and Return on Equity (RoE). Company year observations for these variables for the period 2001 to 2010 were extracted from the McGregor BFA database. The entities were selected based on three criteria: 1) All multiples are positive; i.e. multiples with negative values were discarded, 2) The entities have at least three years of positive company year multiples, and 3) Each industry classification category has at least four observations that meet criteria 1) and 2) above.

A further filter was applied to remove observations located outside of the $1^{\text {st }}$ and $99^{\text {th }}$ percentiles from the pooled observations. This filter was applied specifically to eliminate extreme positive outliers, which could potentially distort the research results. This stems from the design of the study, which limits the downside risk of the valuations, i.e. they cannot be smaller than zero, but does not limit the upside risk of the valuations. Therefore, since the valuation errors could potentially be substantially larger than zero, the risk of distortion is on the upside. However, to prevent a biased outcome, the filter was applied on the upper and the lower ends of the pooled observations. The reasoning for this is two-fold. Firstly, excluding extreme observations will prevent the severe distortion of the research results, since the initial analysis indicated the prevalence of a significant number of outliers (Nel et al., 2013a, b). Secondly, rational investment practitioners will most certainly exclude these extreme observations when estimating peer group multiples in practice.

Note that the determination of an optimal peer group selection strategy requires the creation of peer groups based on different valuation fundamentals or combinations thereof and different industry classifications. Unfortunately, the original form of the data, as extracted from the McGregor BFA database, was not ready-for-use for the purpose of answering the research question. Consequently, the data had to be reworked substantially in order to prepare it for this study. To this end, 14 functions were coded in the $R$-package for the preparation and analysis of the data. The outputs from these functions were tested before they were applied to the data. The purpose of coding these functions was two-pronged: firstly, to prepare the data for data analysis and secondly, to calculate and analyze the valuation errors. The final population of observations represents approximately $71 \%$ of the total number of listed entities on the JSE as at 31 December 2010 and approximately $91 \%$ of the market capitalization of the entities listed on the JSE at the same date, which serves as a fair representation for the conclusions drawn. Although various potential combinations of the market price and value drivers exist, the focus in this study was on 16 multiples within each of the five most popular value driver categories, namely earnings, dividends, assets, revenue and cash flows (Nel, 2010; PwC, 2010; Nel, 2009a; Liu, Nissim and Thomas, 2002b; Cheng and McNamara, 2000). The framework of multiples; i.e. the ratio of the MPVs to the respective value drivers, that was used in the analysis is summarized in Table 1. 
Table 1: Framework of multiples

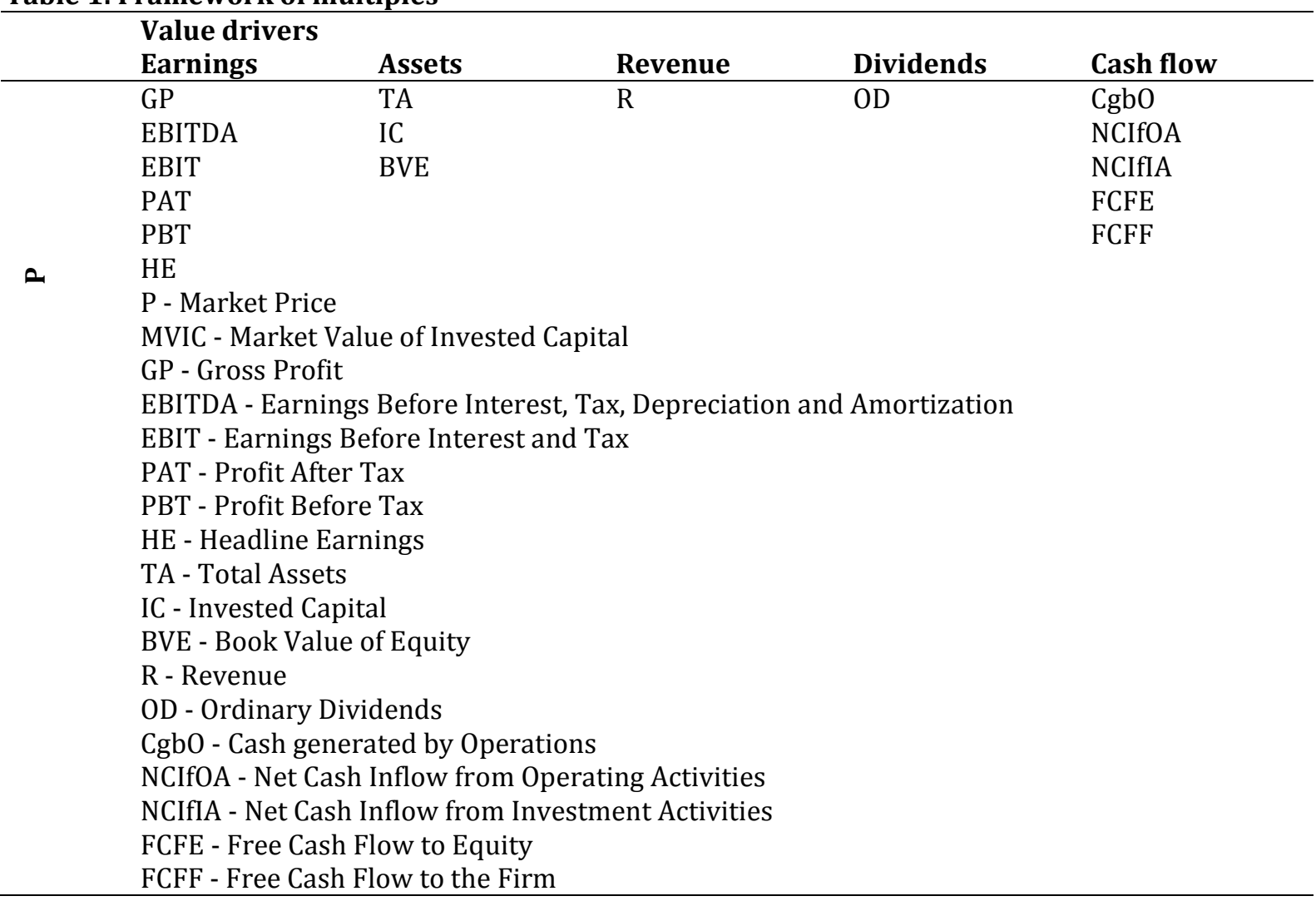

Source: PwC (2012), Minjina (2008), Damodaran (2006a), Liu et al. (2002b), Alford (1992)

The number of observations varied for each of the 16 multiples, depending on the peer group selection method applied and how well the multiples satisfied the criteria stipulated above. Consequently, the population sizes of the multiples vary between 433 and 2684 observations, culminating in a total population size of 260982 observations. From these observations, 16 price-multiples were constructed.

\section{Methodology}

The construction of multiples based on a target company's industry classification is a common phenomenon (Nel et al., 2013a; Nel, 2009a; 2009b; Goedhart et al., 2005; Liu, Nissim and Thomas, 2002a; Fernández, 2001; Barker, 1999). So, too, is a multiples-based valuation approach where peer groups are based on valuation fundamentals (Henschke and Homburg, 2009; Dittmann and Weiner, 2005; Goedhart et al., 2005; Herrmann and Richter, 2003; Bhojraj and Lee, 2002). The methodology applied in this paper is largely adopted from Nel et al. $(2013 a, b)$. However, the focus in this paper is on equity multiples in particular and the peer group selection process focuses on both industry classifications and valuation fundamentals. Valuation theory states that the Actual equity value ( $\left.V_{i t}^{e}\right)$ of a company $(i)$ at a given point in time $(t)$ is equal to the product of an Actual equity-based multiple $\left(\lambda_{t}^{e}\right)$ and a specific Actual value driver $\left(\alpha_{i t}\right)$ at that specific point in time, so that

$V_{i t}^{e}=\lambda_{t}^{e} \cdot \alpha_{i t}$

The objective of this study is to quantify the ability of Equation (1) to approximate actual share prices on the JSE. To this end, an out-of-sample equity-based peer group multiple $\left(\hat{\lambda}_{p t}^{e}\right)$ is estimated for each company by calculating the harmonic mean of all the other remaining entities in a particular peer group. The SUB-based, P/PAT peer group multiple estimate for company A, for example, in a SUB-based peer group that contains entities $A$ to $E$, would therefore be equal to the harmonic mean of the $\mathrm{P} / \mathrm{PAT}$ multiples of entities B to E. The peer group multiples are estimated based on the harmonic mean since it avoids the upward bias of the arithmetic mean and is regarded as a viable and unbiased estimator (Dittmann and Maug, 2008; Bhojraj and Lee, 2002; Liu et al., 2002b; Beatty et al., 1999). 
The peer groups are based on four industry classifications, namely IND, SUP, SEC and SUB; and three proxies for the valuation fundamentals, namely profitability, risk and growth. The proxies for these three variables, namely RoE, TA and Revenue growth $(\mathrm{Rg})$, were used individually and in combination, culminating in seven possibilities. The seven valuation fundamentals comprised three single factor valuation fundamentals, namely RoE, TA and Rg; and three combinations of valuation fundamentals, namely RoE. TA, RoE. Rg and TA. Rg. These four industry classifications and six valuation fundamentals were used to create peer groups for the construction of the 16 multiples contained in Table 1 . The out-ofsample multiple $\left(\hat{\lambda}_{p t}^{e}\right)$ is estimated for each company by calculating the harmonic mean of all the companies in the peer group concerned for that specific multiple. The estimated peer group multiple of each company $\left(\hat{\lambda}_{p t}^{e}\right)$ is then multiplied by the company's actual value driver $\left(\alpha_{i t}\right)$ to calculate an equity value prediction $\left(\hat{V}_{i t}^{e}\right)$ :

$$
\hat{V}_{i t}^{e}=\hat{\lambda}_{c t}^{e} \cdot \alpha_{i t}
$$

Subtracting Equation (2) from Equation (1) produces (3) for the calculation of the error margin (valuation error):

$$
\hat{V}_{i t}^{e}-V_{i t}^{e}
$$

Since companies with higher values will tend to have higher valuation errors, (3) will not be independent of value. It is anticipated that expressing (3) proportionally to $V_{i t}^{e}$ will improve the efficacy of the peer group multiple estimate (Beatty, Riffe and Thompson, 1999). The standardized form of (3), $\varepsilon_{i t}$, is therefore expressed proportionally to $V_{i t}^{e}$, where ${ }^{1}$

$$
\varepsilon_{i t}=\left|\frac{\hat{V}_{i t}^{e}-V_{i t}^{e}}{V_{i t}^{e}}\right|
$$

The valuation errors are calculated for each company year and subsequently aggregated. Absolute valuation errors are used since the results of central tendency measures, such as the mean, will be obscured if positive and negative valuation errors are netted, which may result in an artificially low valuation error.

The superior valuation fundamental, i.e. the valuation fundamental that produces the most accurate equity valuation, will typically be the one with the lowest summarized valuation error. This allows for the construction of a PGV value chain, which indicates the extent to which the valuation precision of multiples improved, depending on the choice of PGV. The PGV value chain indicates the potential percentage improvement (IMP) in valuation precision that may be secured by employing the optimal PGV (a PGV that has the smallest $\varepsilon_{\mathrm{it}}$ ) instead of any of the sub-optimal choices (a PGV that does not have the smallest $\varepsilon_{\mathrm{it}}$ ).

\section{Results}

A comparison of the relative valuation performances of the multiples, whose peer groups are based on the two schools of thought, as discussed in Section 3, offers insight as to the ideal basis for an optimal peer group selection strategy for multiples-based valuation purposes. A PCA biplot is employed to visualise the relative valuation performance of these two schools of thought, while the correlations between the ten different PGVs is measured by the use of a correlation monoplot. It is hoped that a specific type of, and particular, PGV will emerge as the optimal basis for peer group selection purposes. In order to gain a clear perspective on the relative valuation performance of the 16 multiples, a PGV value chain is created, ranking, for each of the 16 multiples, the ten PGVs according to their respective valuation accuracies.

1 Functions for the calculation of $\varepsilon_{i t}$ and the statistical analysis thereof were developed in the Rpackage, an open source programming language that lends itself to statistical analysis and graphics (R Core Team, 2014). 
Peer group selection based on valuation fundamentals and industry classification: A summary of the absolute valuation errors of the 16 multiples whose peer groups were based on each of the ten different PGVs is contained in Table 2. The multi-dimensional nature of the data contained in Table 2 complicates a careful analysis of the general trend of the data. Since the data occupies multi-dimensional space, i.e. it encapsulates multiple coordinate axes; the use of a conventional, two-dimensional scatter plot is inappropriate (Gower, Lubbe and Le Roux, 2011). However, the use of biplots accommodates higher-dimensional data by approximating it in lower, usually two-dimensional space, thereby enabling the visualisation of multi-dimensional data. The overall valuation performance depicted in Figure 1 suggests that multiples whose peer groups are based on a combination of valuation fundamentals seem to produce more accurate valuations vis-á-vis multiples whose peer groups are based on industry classification. However, none of the PGVs consistently produced the most accurate valuations across all 16 multiples. Valuation fundamentals-based multiples produced the most accurate valuations for $81.25 \%$ of the multiples, while industry classification-based multiples produced the most accurate valuations for $18.75 \%$ of the multiples, i.e. for the three multiples

Table 2: Actual valuation errors of 16 multiples whose peer groups were based on 10 different PGVs

\begin{tabular}{|c|c|c|c|c|c|c|c|c|c|c|}
\hline Multiple & $\begin{array}{l}\text { PGV } \\
\text { RoE } \\
\end{array}$ & TA & Rg & RoE. TA & RoE. Rg & TA. Rg & IND & SUP & SEC & SUB \\
\hline GP & 0.6496 & 0.6548 & 0.6638 & 0.5614 & 0.5977 & 0.6020 & 0.6438 & 0.6190 & 0.6178 & 0.6299 \\
\hline EBITDA & 0.5275 & 0.5731 & 0.5335 & 0.4015 & 0.3911 & 0.4244 & 0.5025 & 0.4835 & 0.4754 & 0.4591 \\
\hline EBIT & 0.5125 & 0.5446 & 0.4987 & 0.3821 & 0.3688 & 0.4020 & 0.4657 & 0.4398 & 0.4383 & 0.4249 \\
\hline PAT & 0.4860 & 0.5717 & 0.5306 & 0.3750 & 0.3688 & 0.4520 & 0.4308 & 0.4232 & 0.4188 & 0.4199 \\
\hline PBT & 0.4581 & 0.5320 & 0.5131 & 0.3382 & 0.3323 & 0.4338 & 0.4209 & 0.4083 & 0.4061 & 0.4065 \\
\hline $\mathrm{HE}$ & 0.4028 & 0.4237 & 0.4154 & 0.2956 & 0.2888 & 0.3565 & 0.3130 & 0.3140 & 0.3156 & 0.3375 \\
\hline TA & 0.6108 & 0.6300 & 0.6274 & 0.4844 & 0.4716 & 0.5630 & 0.6278 & 0.6007 & 0.5753 & 0.5706 \\
\hline IC & 0.6246 & 0.6508 & 0.6477 & 0.5184 & 0.4950 & 0.5830 & 0.6526 & 0.6264 & 0.5957 & 0.5937 \\
\hline $\mathrm{BE}$ & 0.4888 & 0.6495 & 0.6400 & 0.3852 & 0.3782 & 0.6246 & 0.5770 & 0.5750 & 0.5918 & 0.5824 \\
\hline $\mathrm{R}$ & 0.6737 & 0.6951 & 0.6991 & 0.5734 & 0.6070 & 0.6824 & 0.6782 & 0.6398 & 0.6316 & 0.6249 \\
\hline CgbO & 0.5918 & 0.5919 & 0.5405 & 0.4689 & 0.4049 & 0.4461 & 0.4989 & 0.4984 & 0.4998 & 0.5104 \\
\hline NCIfOA & 0.7458 & 0.7879 & 0.7342 & 0.6343 & 0.5679 & 0.6961 & 0.5964 & 0.6144 & 0.6194 & 0.6168 \\
\hline NCIfIA & 1.1020 & 1.1825 & 1.1159 & 1.0832 & 1.0357 & 1.2138 & 0.7594 & 0.7777 & 0.7692 & 0.8160 \\
\hline OD & 0.5085 & 0.5534 & 0.5175 & 0.5012 & 0.4446 & 0.5119 & 0.5109 & 0.5446 & 0.5358 & 0.5625 \\
\hline FCFE & 0.9653 & 1.0349 & 1.0154 & 0.8850 & 0.8448 & 1.0251 & 0.6842 & 0.6802 & 0.6859 & 0.7135 \\
\hline FCFF & 0.8607 & 0.9228 & 0.8306 & 0.7368 & 0.7133 & 0.7690 & 0.6056 & 0.6158 & 0.6288 & 0.6509 \\
\hline
\end{tabular}


Fig 1: PCA biplot of multiples whose peer groups are based on 10 different PGVs (colour-coded)

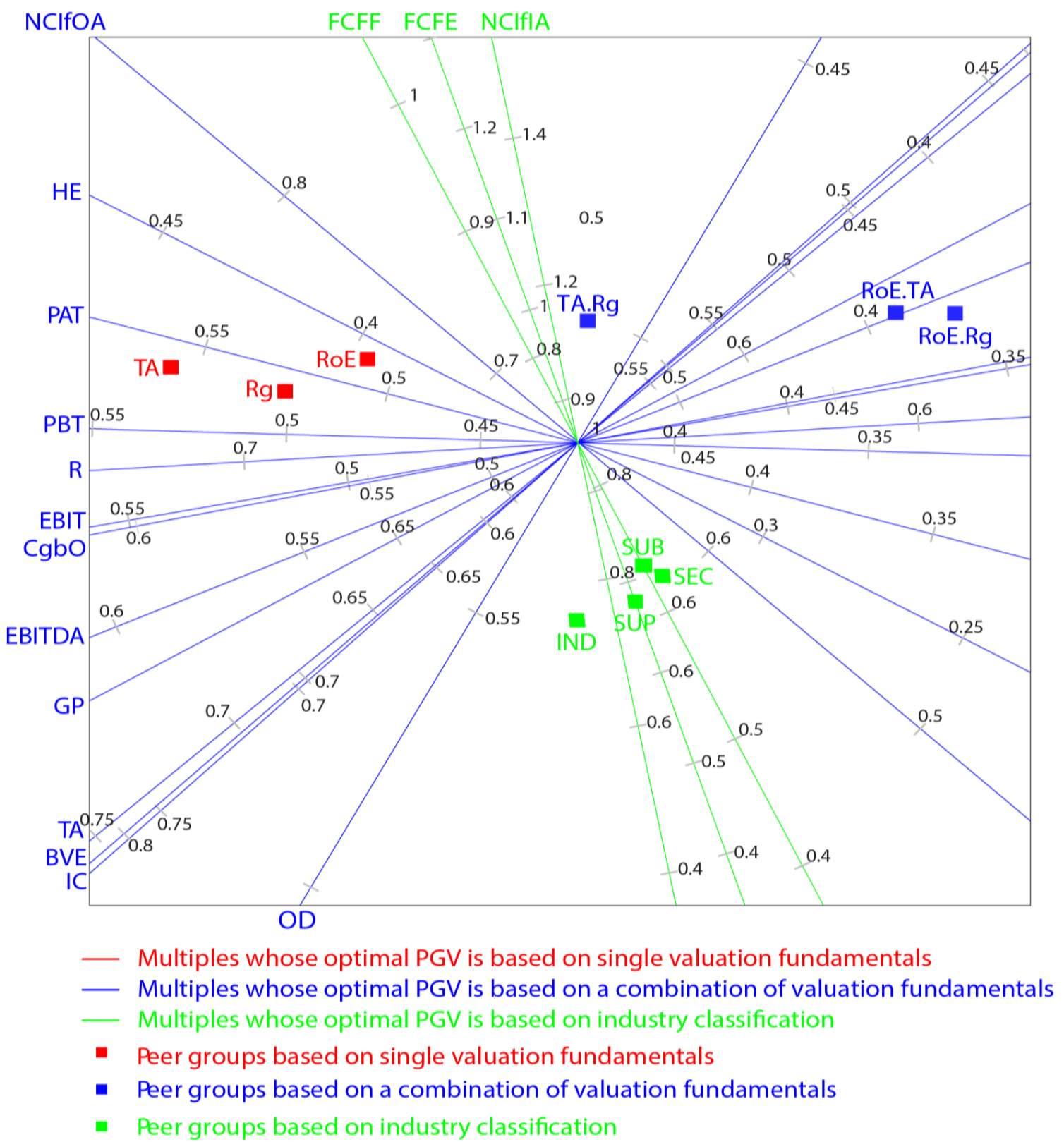

NCIFIA, FCFE AND FCFF. The latter is evident from the colour-coded axes in Figure 1, which depict the PGV basis which produced the most accurate valuations for each multiple.

However, a distinction should be made among the valuation fundamentals-based peer groups. As concluded by Nel et al. (2014a), multiples whose peer groups are based on a combination of valuation fundamentals generally produced more accurate valuations than multiples whose peer groups are based on single valuation fundamentals. This is evident from the location of the three single valuation fundamental PGVs, RoE, Rg and TA, relative to their combination of valuation fundamentals-based counterparts, TA. Rg, RoE. TA and RoE. Rg. Note that, among the combination of valuation fundamentals, TA. Rg produced far less accurate valuations than RoE. TA and RoE. Rg, which is reflected in its location a substantial distance from RoE.TA and RoE. Rg. TA. Rg is the only combination of valuation fundamentals-based peer group that occasionally produced less accurate valuations than one or more of the single valuation fundamentals, as was the case with the NCIfIA multiple, for example. One should also consider the location of the 10 PGVs relative to the origin. It is evident that single valuation fundamentals generally produced the least accurate results, since they are located the furthest to the left of, and slightly above, the origin. However, single valuation fundamentals occasionally offered a moderate valuation performance by producing valuations that were more accurate than one or more of the industry-based PGVs. RoE, for example, did so for the BVE multiple. 
Industry-based peer groups generally offered a moderate degree of valuation precision, since they clustered together at the level of the origin. However, three notable exceptions occurred in the case of the multiples NCIfIA, FCFE and FCFF, where the location of the industry-based peer groups were the furthest below the origin, i.e. for these three multiples, they produced the most accurate valuations. The combination of valuation fundamentals-based peer groups generally offered the highest degree of valuation precision, since they were located the furthest to the right of the origin. The exception was TA. $\mathrm{Rg}$, which was located further to the left of RoE. TA and RoE. Rg and closer to the origin, reflecting it's generally moderate degree of valuation precision. Note that the biplot in Figure 1 does not display the actual data set, as contained in Table 2, which, geometrically, lies in a ten-dimensional space, but rather an approximation of the data in two dimensions. Although a certain loss of information is, therefore, inevitable when employing biplots, they are able to accommodate more than two variables in the form of calibrated axes, which would not be able to intersect orthogonally in two dimensions. Although the PCAbased biplot in Figure 1 approximates the data in the best possible two-dimensional space, the reduction of the multi-dimensionality of the data culminates in a loss of data accuracy (Greenacre, 2007). If the loss of information resulting from this approximation is negligible, much can be learned about the multidimensional nature of the data. Consequently, it is also necessary to evaluate the quality of the PCA biplots.

Table 3: Predictivity readings over 16 multiples

\begin{tabular}{ll}
\hline Multiple & Predictivity \\
\hline GP & 0.822 \\
EBITDA & 0.928 \\
EBIT & 0.910 \\
PAT & 0.979 \\
PBT & 0.979 \\
HE & 0.969 \\
TA & 0.963 \\
IC & 0.957 \\
BE & 0.703 \\
R & 0.773 \\
CgbO & 0.765 \\
NCIfOA & 0.952 \\
NCIfIA & 0.972 \\
OD & 0.573 \\
FCFE & 0.974 \\
FCFF & 0.970 \\
\hline
\end{tabular}

The quality of the PCA biplots: In order to assess the loss of information accompanying the use of PCA biplots, one must consider the biplot's overall quality of display, the accuracy of its calibrated axes and that of its sample predictions. A higher overall quality of display reading reflects a less significant loss in data accuracy and vice versa. In Figure 1, the quality of display is $88.67 \%$, which reflects the proportion of the total variation in the data accounted for in the remaining eight dimensions. The accuracy of the approximations of the individual axes in the biplot is known as the axes' productivities. These values, which can be obtained from the output of the PCAbipl function in the R-package, are contained in Table $3 .^{2}$ From Table 3, it is evident that the greatest loss in accuracy occurs with OD and, at 57.3\%; it indicates

2 The $R$ code for constructing the PCA biplots utilizes the UBbipl package, which is available at the following link http://dl.dropbox.com/u/17860902/UBbipl_1.0.zip 
that the presentation of OD is the poorest of all the multiples. The quality of display reading of $88.67 \%$ and the axes' Predictivity readings, as contained in Table 3, confirmed a negligible loss of data accuracy. Predictions can be read from the PCA biplot by projecting from a sample point onto any axes and obtaining a reading from the nearest marker on these axes. A good approximation will result in good predictions. The approximations of the actual data points, as displayed in Figure 2, together with the actual data points, are contained in Table 4. As is evident, the Actual (Act) and Predicted (Pre) values are very similar.

Table 4: PGVs: Actual (Act) and Predicted (Pre) valuation errors over 16 multiples

\begin{tabular}{|c|c|c|c|c|c|c|c|c|c|c|}
\hline \multirow[t]{3}{*}{ Multiple } & \multicolumn{10}{|l|}{ PGV } \\
\hline & \multicolumn{2}{|l|}{ RoE } & \multicolumn{2}{|l|}{ TA } & \multicolumn{2}{|l|}{$\mathbf{R g}$} & \multicolumn{2}{|l|}{ RoE.TA } & \multicolumn{2}{|l|}{ RoE. Rg } \\
\hline & & Pre & Act & Pre & Act & Pre & Act & Pre & & Pre \\
\hline GP & 0.6496 & 0.6369 & 0.6548 & 0.6624 & 0.6638 & 0.6517 & 0.5614 & 0.5808 & 0.5977 & 0.5742 \\
\hline EBITDA & 0.5275 & 0.5068 & 0.5731 & 0.5598 & 0.5335 & 0.5367 & 0.4015 & 0.3922 & 0.3911 & 0.3777 \\
\hline EBIT & 0.5125 & 0.4809 & 0.5446 & 0.5327 & 0.4987 & 0.5087 & 0.3821 & 0.3725 & 0.3688 & 0.3573 \\
\hline PAT & 0.4860 & 0.4972 & 0.5717 & 0.5589 & 0.5306 & 0.5269 & 0.3750 & 0.3770 & 0.3688 & 0.3562 \\
\hline PBT & 0.4581 & 0.4701 & 0.5320 & 0.5326 & 0.5131 & 0.5018 & 0.3382 & 0.3442 & 0.3323 & 0.3245 \\
\hline $\mathrm{HE}$ & 0.4028 & 0.3873 & 0.4237 & 0.4334 & 0.4154 & 0.4081 & 0.2956 & 0.3011 & 0.2888 & 0.2845 \\
\hline $\mathrm{TA}$ & 0.6108 & 0.5968 & 0.6300 & 0.6453 & 0.6274 & 0.6263 & 0.4844 & 0.4865 & 0.4716 & 0.4749 \\
\hline IC & 0.6246 & 0.6172 & 0.6508 & 0.6626 & 0.6477 & 0.6451 & 0.5184 & 0.5129 & 0.4950 & 0.5023 \\
\hline BVE & 0.4888 & 0.5824 & 0.6495 & 0.6571 & 0.6400 & 0.6274 & 0.3852 & 0.4132 & 0.3782 & 0.3950 \\
\hline $\mathrm{R}$ & 0.6737 & 0.6756 & 0.6951 & 0.7114 & 0.6991 & 0.6940 & 0.5734 & 0.6026 & 0.6070 & 0.5915 \\
\hline CgbO & 0.5918 & 0.5357 & 0.5919 & 0.5839 & 0.5405 & 0.5617 & 0.4689 & 0.4344 & 0.4049 & 0.4204 \\
\hline NCIfOA & 0.7458 & 0.7244 & 0.7879 & 0.7870 & 0.7342 & 0.7502 & 0.6343 & 0.6138 & 0.5679 & 0.5895 \\
\hline NCIfIA & 1.1020 & 1.1236 & 1.1825 & 1.1829 & 1.1159 & 1.1217 & 1.0832 & 1.0877 & 1.0357 & 1.0442 \\
\hline OD & 0.5085 & 0.5223 & 0.5534 & 0.5402 & 0.5175 & 0.5347 & 0.5012 & 0.4775 & 0.4446 & 0.4744 \\
\hline FCFE & 0.9653 & 0.9795 & 1.0349 & 1.0547 & 1.0154 & 0.9936 & 0.8850 & 0.8908 & 0.8448 & 0.8484 \\
\hline FCFF & 0.8607 & 0.8277 & 0.9228 & 0.8963 & 0.8306 & 0.8475 & 0.7368 & 0.7285 & 0.7133 & 0.6953 \\
\hline \multicolumn{11}{|l|}{ Tab } \\
\hline Multiple & $\begin{array}{l}\text { PGV } \\
\text { TA. Rg }\end{array}$ & & IND & & SUP & & SEC & & SUB & \\
\hline & Act & Pre & Act & Pre & Act & Pre & Act & Pre & Act & Pre \\
\hline GP & 0.6020 & 0.6164 & 0.6438 & 0.6353 & 0.6190 & 0.6292 & 0.6178 & 0.6274 & 0.6299 & 0.6255 \\
\hline EBITDA & 0.4244 & 0.4668 & 0.5025 & 0.4943 & 0.4835 & 0.4824 & 0.4754 & 0.4789 & 0.4591 & 0.4761 \\
\hline EBIT & 0.4020 & 0.4457 & 0.4657 & 0.4546 & 0.4398 & 0.4441 & 0.4383 & 0.4410 & 0.4249 & 0.4401 \\
\hline PAT & 0.4520 & 0.4651 & 0.4308 & 0.4317 & 0.4232 & 0.4221 & 0.4188 & 0.4193 & 0.4199 & 0.4225 \\
\hline PBT & 0.4338 & 0.4329 & 0.4209 & 0.4204 & 0.4083 & 0.4093 & 0.4061 & 0.4061 & 0.4065 & 0.4072 \\
\hline
\end{tabular}




\begin{tabular}{lllllllllll}
\hline HE & 0.3565 & 0.3672 & 0.3130 & 0.3246 & 0.3140 & 0.3187 & 0.3156 & 0.3169 & 0.3375 & 0.3210 \\
TA & 0.5630 & 0.5541 & 0.6278 & 0.6072 & 0.6007 & 0.5944 & 0.5753 & 0.5907 & 0.5706 & 0.5855 \\
IC & 0.5830 & 0.5762 & 0.6526 & 0.6303 & 0.6264 & 0.6179 & 0.5957 & 0.6143 & 0.5937 & 0.6091 \\
BVE & 0.6246 & 0.5175 & 0.5770 & 0.5943 & 0.5750 & 0.5748 & 0.5918 & 0.5691 & 0.5824 & 0.5616 \\
R & 0.6824 & 0.6534 & 0.6782 & 0.6501 & 0.6398 & 0.6435 & 0.6316 & 0.6415 & 0.6249 & 0.6418 \\
CgbO & 0.4461 & 0.5026 & 0.4989 & 0.5123 & 0.4984 & 0.5025 & 0.4998 & 0.4996 & 0.5104 & 0.4986 \\
NCIfOA & 0.6961 & 0.7043 & 0.5964 & 0.6141 & 0.6144 & 0.6083 & 0.6194 & 0.6065 & 0.6168 & 0.6151 \\
NCIfIA & 1.2138 & 1.1802 & 0.7594 & 0.7528 & 0.7777 & 0.7704 & 0.7692 & 0.7753 & 0.8160 & 0.8166 \\
OD & 0.5119 & 0.5021 & 0.5109 & 0.5413 & 0.5446 & 0.5353 & 0.5358 & 0.5335 & 0.5625 & 0.5297 \\
FCFE & 1.0251 & 1.0039 & 0.6842 & 0.6761 & 0.6802 & 0.6838 & 0.6859 & 0.6860 & 0.7135 & 0.7175 \\
FCFF & 0.7690 & 0.8299 & 0.6056 & 0.6215 & 0.6158 & 0.6224 & 0.6288 & 0.6226 & 0.6509 & 0.6427 \\
\hline
\end{tabular}

The comparison between the actual and predicted data points over all 16 multiples in Table 4 indicates that the loss in data accuracy is negligible. The predictions contained in Table 4 can be read from the PCA biplot displayed in Figure 2. As is evident from Figure 2, projecting all the sample predictions on a biplot would cluster the display and seems nonsensical. However, consider the perpendicular readings of the PGV RoE.Rg, for example, from Figure 3.

Figure 2: PCA biplot of multiples whose peer groups are based on 10 different PGVs (all sample predictions included)

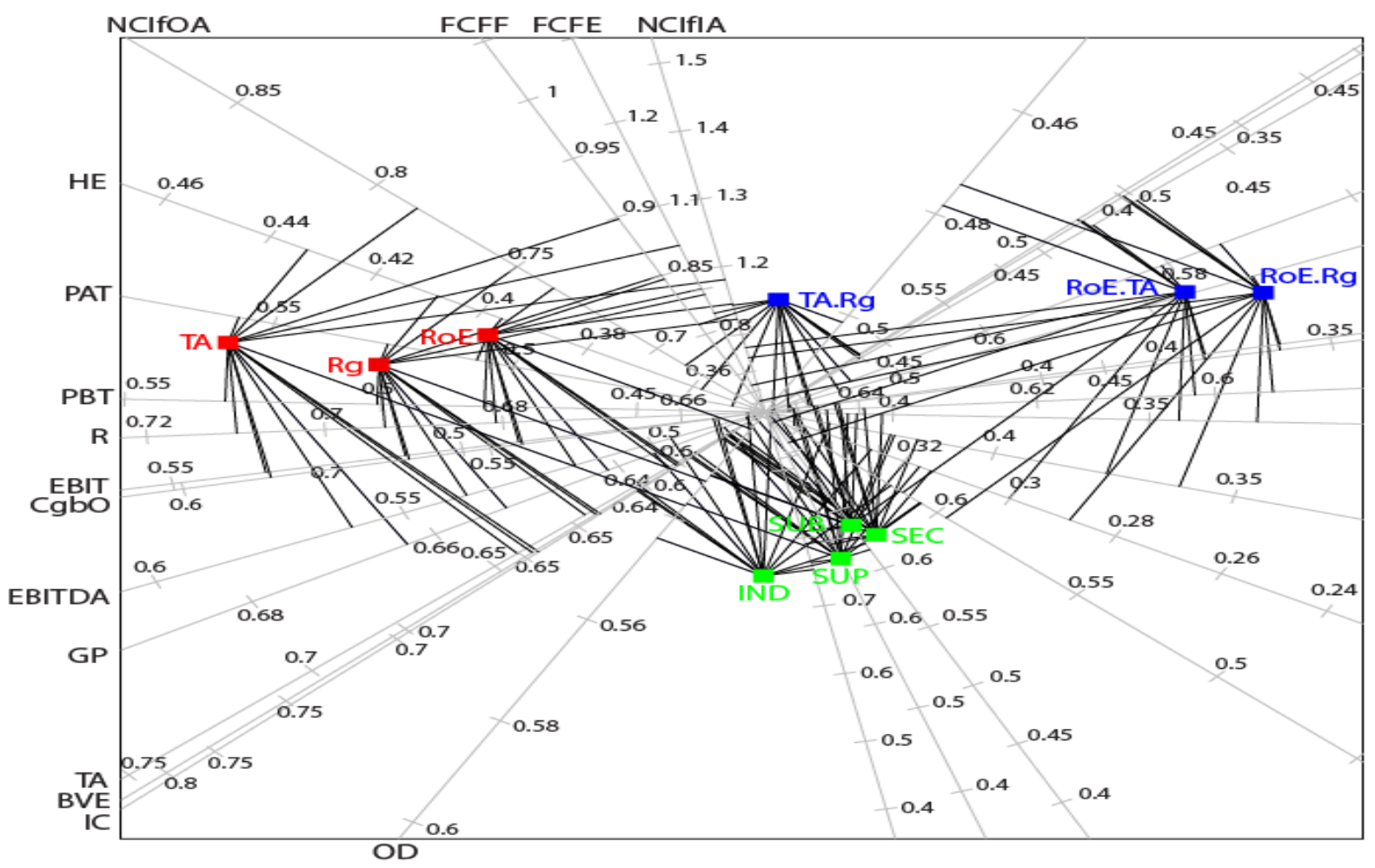


Figure 3: PCA biplot of multiples whose peer groups are based on 10 different PGVs (RoE.Rg sample predictions included)

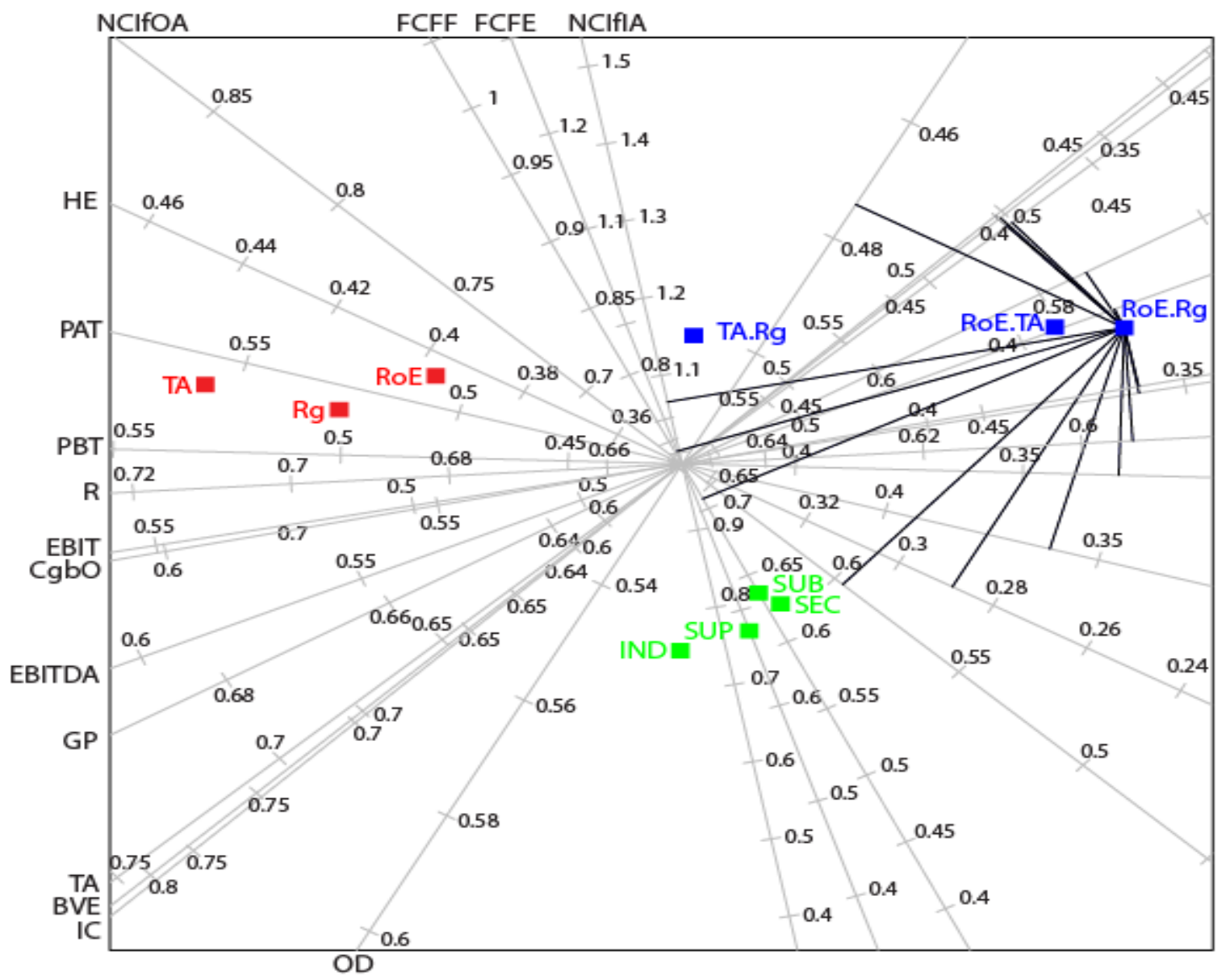

The projection onto the OD axis, for example, indicates a reading somewhere between 0.46 and 0.48 , but somewhat closer to 0.48 than to 0.46 , which corresponds to the 0.4744 prediction in Table 4 . Although not shown here, similar readings can be traced to Table 4 for all 15 other multiples. If an exact reading from the biplot is required, it can be achieved algebraically. By default, PCA biplots constructed with UBBipl optimise the relative distances between the positions of the data points and their relationships with the calibrated axes. However, the default setting of the PCA biplots do not optimise the correlations between the calibrated axes, as reflected by the angles between them. Although the angles between these axes are indications of the correlations among the PGVs, these angles are not optimised. To gain an accurate representation of the correlations, a correlation monoplot is required.

Correlations among the PGVs: In order to gain an understanding of the correlations between the 10 PGVs, one has to transpose the data matrix, as contained in Table 2. The inter-correlations within and between each of the three PGV categories is depicted in the correlation monoplot in Figure 4. 


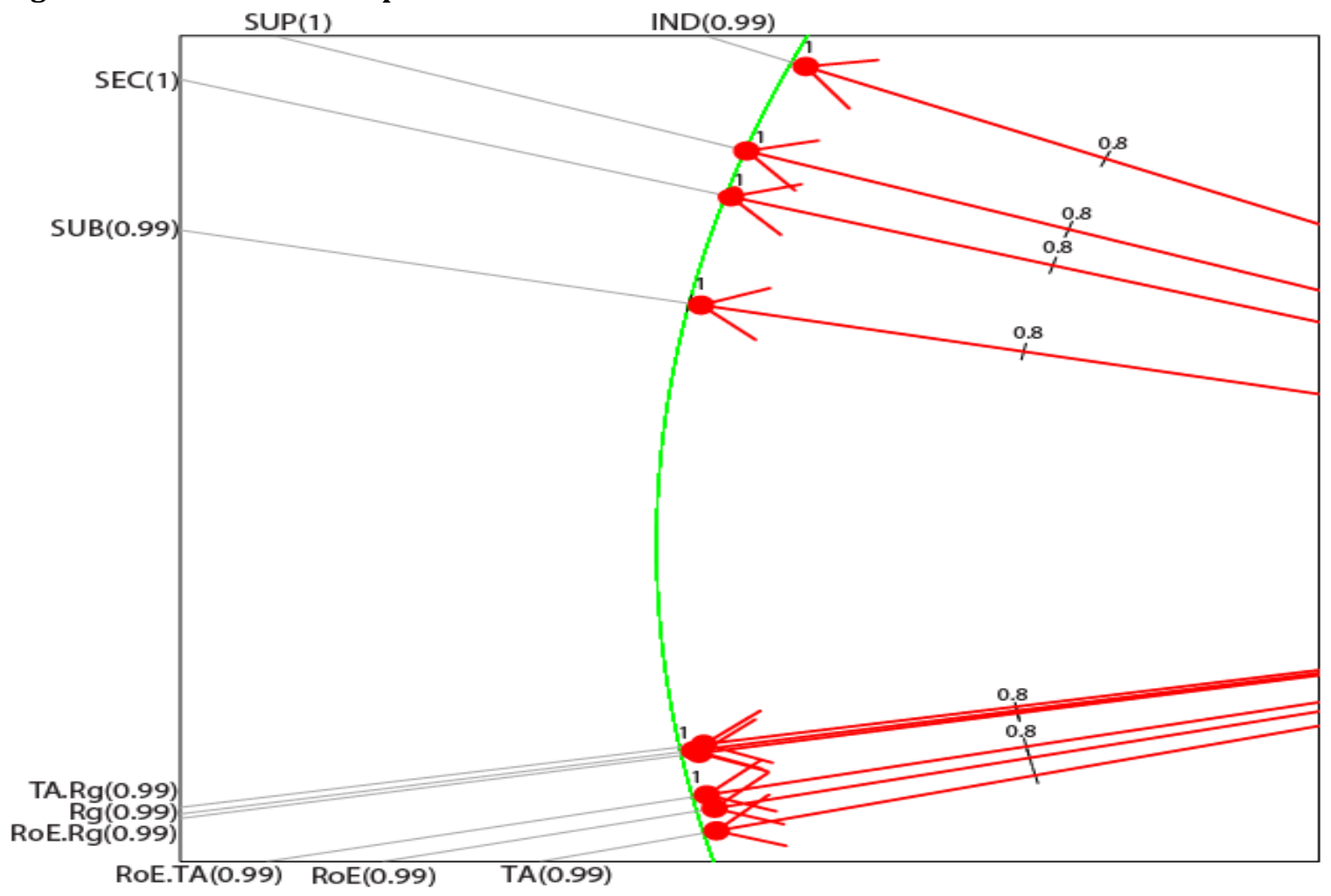

From the degree of approximations (indicated in parenthesis) it is clear that the correlation monoplot approximates the PGVs very well, since they all have values of 0.99 or higher. All 10 PGVs are positively correlated. The inter-correlations between two of the three combinations of valuation fundamentals, namely TA.Rg and RoE.Rg, are particularly highly positively correlated, almost to the extent that they overlap each other. Although RoE.TA is also highly positively correlated with TA.Rg and RoE.Rg, it is positioned at a wider angle from TA.Rg and RoE.Rg. While the inter-correlations between the three single valuation fundamentals are also highly positive, the positive inter-correlations between the industries classification-based PGVs are far weaker. Equally evident is the weak positive correlation between the valuation fundamentals-based PGVs and the industry classification-based PGVs. This is in line with the superior valuation performance of the multiples whose peer groups were based on valuation fundamentals, particularly a combination of valuation fundamentals, rather than on industry classification. The question that remains is whether any of the ten PGVs emerged as the de facto PGV of choice and whether these differences in valuation performance among the ten PGVs are substantial.

Optimal PGVs and potential gains in valuation precision: From the relative positions of the 10 PGVs in Figure 1, it is evident that the magnitude of the difference in relative valuation performance of the 10 PGVs is substantial. A comparison between the valuation precision of multiples whose peer groups are based on valuation fundamentals with that of multiples whose peer groups are based on industry classification is summarised in Table 5. The 10 PGVs, six valuation fundamentals and four industry classifications, are ranked from least accurate PGV to the most accurate PGV, indicating the IMP that may be secured when substituting each sub-optimal choice of PGV with the optimal PGV. Therefore, the least accurate choice of PGV is situated furthest to the left of Table 5 and carries the highest IMP in valuation precision, while the optimal choice of PGV is situated furthest to the right and carries no IMP, i.e. the IMP is zero. 
Table 5: IMP in the median valuation errors based on 10 PGVs

\begin{tabular}{|c|c|c|c|c|c|c|c|c|c|c|}
\hline \multicolumn{11}{|c|}{ GP } \\
\hline Peer group & $\mathrm{Rg}$ & TA & RoE & IND & SUB & SUP & SEC & & & \\
\hline IMP & $15.43 \%$ & $14.26 \%$ & $13.58 \%$ & $12.80 \%$ & $10.87 \%$ & $9.31 \%$ & $9.13 \%$ & $6.74 \%$ & 5. & 0.0 \\
\hline $\mathbf{N}$ & 1963 & 2415 & 2176 & 2356 & 1790 & 2338 & 2235 & 60 & & \\
\hline \multicolumn{11}{|c|}{ EBITDA } \\
\hline Peer group & TA & $\mathrm{Rg}$ & RoE & IND & SUP & SEC & SUB & & & \\
\hline IMP & $31.76 \%$ & $26.69 \%$ & $25.86 \%$ & $22.17 \%$ & $19.11 \%$ & $17.73 \%$ & $14.81 \%$ & 7.85 & & 0.00 \\
\hline $\mathbf{N}$ & 2634 & 1989 & 2395 & 2345 & 2328 & 2229 & 1768 & 603 & & $n^{2}+3$ \\
\hline \multicolumn{11}{|c|}{ EBIT } \\
\hline Peer group & TA & RoE & $\mathrm{Rg}$ & IND & SUP & SEC & SUB & & & \\
\hline IMP & $32.28 \%$ & $28.04 \%$ & $26.05 \%$ & $20.81 \%$ & $16.14 \%$ & $15.86 \%$ & $13.20 \%$ & 3.26 & 3.48 & 0.00 \\
\hline $\mathbf{N}$ & 2620 & 2370 & 1979 & 2276 & 2259 & 2161 & 1723 & 601 & 775 & 812 \\
\hline \multicolumn{11}{|c|}{ PAT } \\
\hline Peer group & TA & $\mathrm{Rg}$ & RoE & & IND & SUP & SUB & SEC & & \\
\hline IMP & $35.49 \%$ & $30.49 \%$ & $24.12 \%$ & $18.41 \mathrm{~s}$ & $14.39 \%$ & $12.85 \%$ & $12.17 \%$ & $11.94 \%$ & & 0.00 \\
\hline $\mathbf{N}$ & 2619 & 1965 & 2310 & 58 & 2128 & 2112 & 1609 & 2015 & & \\
\hline \multicolumn{11}{|c|}{ PBT } \\
\hline Peer group & TA & Rg & RoE & & IND & SUP & SUB & SEC & & \\
\hline IMP & $37.54 \%$ & $35.24 \%$ & $27.46 \%$ & $23.40^{\circ}$ & $21.05 \%$ & $18.61 \%$ & $18.25 \%$ & $18.17 \%$ & & \\
\hline $\mathbf{N}$ & 2619 & 1965 & 2306 & 589 & 2159 & 2142 & 1613 & 2043 & 767 & 810 \\
\hline \multicolumn{11}{|c|}{$\mathrm{HE}$} \\
\hline Peer group & TA & $\mathrm{Rg}$ & RoE & & SUB & SEC & SUP & IND & & \\
\hline IMP & $31.84 \%$ & $30.48 \%$ & $28.30 \%$ & $18.99 \%$ & $14.43 \%$ & $8.49 \%$ & $8.03 \%$ & $7.73 \%$ & $2.30 \%$ & $0.00^{\circ}$ \\
\hline $\mathbf{N}$ & 2601 & 1960 & 2325 & 589 & 1656 & 2064 & 2162 & 2178 & 776 & \\
\hline \multicolumn{11}{|c|}{ TA } \\
\hline Peer group & TA & IND & $\mathrm{Rg}$ & RoE & SUP & SEC & SUB & & A & \\
\hline IMP & $25.14 \%$ & $24.88 \%$ & $24.83 \%$ & $22.79 \%$ & $21.49 \%$ & $18.03 \%$ & $17.35 \%$ & $16.23 \%$ & $2.64 \%$ & 0.00 \\
\hline $\mathbf{N}$ & 2656 & 2684 & 1993 & 2458 & 2664 & 2589 & 2142 & 609 & 788 & 816 \\
\hline \multicolumn{11}{|l|}{ Peer group } \\
\hline Peer group & IND & TA & $\mathrm{Rg}$ & SUP & RoE & SEC & SUB & & & \\
\hline IMP & $24.15 \%$ & $23.94 \%$ & $23.58 \%$ & $20.98 \%$ & $20.75 \%$ & $16.90 \%$ & $16.62 \%$ & $15.09 \%$ & $4.51 \%$ & $0.00^{\circ}$ \\
\hline $\mathbf{N}$ & 2682 & 2655 & 1997 & 2662 & 2462 & 2588 & 2163 & 611 & 788 & 816 \\
\hline \multicolumn{11}{|c|}{ BVE } \\
\hline Peer group & TA & $\mathrm{Rg}$ & & SEC & SUB & IND & SUP & RoE & & \\
\hline IMP & $41.77 \%$ & $40.91 \%$ & $39.45 \%$ & $36.09 \%$ & $35.06 \%$ & $34.45 \%$ & $34.23 \%$ & $22.63 \%$ & $1.82 \%$ & $0.00 \%$ \\
\hline $\mathbf{N}$ & 2637 & 1964 & 589 & 2303 & 1879 & 2409 & 2389 & 2418 & 784 & 809 \\
\hline \multicolumn{11}{|l|}{ Peer aroun } \\
\hline Peer group & $\mathrm{Rg}$ & TA & & IND & RoE & SUP & SEC & SUB & & \\
\hline IMP & $17.98 \%$ & $17.51 \%$ & $15.97 \%$ & $15.45 \%$ & $14.89 \%$ & $10.38 \%$ & $9.21 \%$ & $8.24 \%$ & 5.5 & $0.00 \%$ \\
\hline $\mathbf{N}$ & 1965 & 2394 & $59 \varepsilon$ & 2386 & 2167 & 2366 & 2263 & 1813 & & 711 \\
\hline \multicolumn{11}{|c|}{ CgbO } \\
\hline Peer group & TA & RoE & $\mathrm{Rg}$ & SUB & SEC & IND & SUP & & & \\
\hline IMP & $31.59 \%$ & $31.58 \%$ & $25.09 \%$ & $20.67 \%$ & $18.99 \%$ & $18.84 \%$ & $18.76 \%$ & $13.65 \%$ & $9.24 \%$ & $0.00 \%$ \\
\hline $\mathbf{N}$ & 2615 & 2369 & 1974 & 1626 & 2012 & 2171 & 2155 & 761 & 596 & 807 \\
\hline \multicolumn{11}{|c|}{ NCIfOA } \\
\hline Peer group & TA & RoE & $\mathrm{Rg}$ & & & SEC & SUB & SUP & IND & \\
\hline IMP & $27.92 \%$ & $23.85 \%$ & $22.65 \%$ & $18.42 \%$ & 10.479 & $8.31 \%$ & $7.93 \%$ & $7.57 \%$ & $4.78 \%$ & $0.00 \%$ \\
\hline $\mathbf{N}$ & 2616 & 2350 & 1964 & 575 & 737 & 1818 & 1425 & 1937 & 1952 & 802 \\
\hline & & & & & NCIfIA & & & & & \\
\hline Peer group & & TA & $\mathrm{Rg}$ & RoE & & & SUB & SUP & SEC & IND \\
\hline IMP & 77.4 & $35.78 \%$ & $31.95 \%$ & $31.09 \%$ & $29.89 \%$ & 26.68 & $6.94 \%$ & $2.35 \%$ & $1.27 \%$ & $0.00 \%$ \\
\hline $\mathbf{N}$ & $-5+3$ & 2577 & 1892 & 2178 & 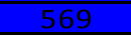 & 75 & 724 & 1094 & 994 & 1110 \\
\hline & & & & & OD & & & & & \\
\hline Peer group & SUB & TA & SUP & SEC & $\mathrm{Rg}$ & & IND & RoE & & \\
\hline IMP & $20.96 \%$ & $19.66 \%$ & $18.36 \%$ & $17.02 \%$ & $14.09 \%$ & 13.15 & $12.98 \%$ & $12.57 \%$ & $11.29 \%$ & $0.00 \%$ \\
\hline $\mathbf{N}$ & 1176 & 1672 & 1661 & 1504 & 1341 & 433 & 1682 & 1529 & 553 & 661 \\
\hline & & & & & FCFE & & & & & \\
\hline Peer group & TA & & $\mathrm{Rg}$ & RoE & & & SUB & SEC & IND & SUP \\
\hline IMP & $34.27 \%$ & $33.65 \%$ & $33.01 \%$ & $29.53 \%$ & $23.14 \%$ & $19.48 \%$ & $4.67 \%$ & $0.83 \%$ & $0.58 \%$ & $0.00 \%$ \\
\hline $\mathbf{N}$ & 2607 & 490 & 1927 & 2196 & 656 & 779 & 921 & 1249 & 1384 & 1372 \\
\hline & & & & & FCFF & & & & & \\
\hline Peer group & TA & RoE & $\mathrm{Rg}$ & & & & SUB & SEC & SUP & IND \\
\hline IMP & $34.37 \%$ & $29.64 \%$ & $27.09 \%$ & $21.25 \%$ & $17.81 \%$ & $15.10 \%$ & $6.96 \%$ & $3.69 \%$ & $1.66 \%$ & $0.00 \%$ \\
\hline $\mathbf{N}$ & 2596 & 2188 & 1928 & 52 & 66 & 787 & 1030 & 1400 & 1544 & 1556 \\
\hline
\end{tabular}

The following can be gleaned from Table 5: Firstly, multiples whose peer groups are based on single valuation fundamentals generally perform the least accurate equity valuations. This is reflected in a suboptimal IMP range of $12.57 \%$ to $41.77 \%$ and the fact that none of the multiples whose peer groups were based on single valuation fundamentals produced the most accurate valuation for any of the 16 multiples. Secondly, multiples whose peer groups are based on industry classifications generally perform more accurate valuations than multiples whose peer groups are based on single valuation fundamentals, but less accurate valuations than multiples whose peer groups are based on a combination of valuation fundamentals. Multiples whose peer groups are based on industry classifications indicate a sub-optimal 
IMP, ranging from $0.58 \%$ to $36.09 \%$, and produced the most accurate valuations for three, or $18.75 \%$, of the multiples, namely NCIfIA, FCFE and FCFF. Thirdly, multiples whose peer groups are based on a combination of valuation fundamentals generally perform more accurate valuations than multiples whose peer groups are based on industry classifications, culminating in a sub-optimal IMP ranging from $1.65 \%$ to $39.45 \%$, and produced the most accurate valuations for 13 , or $81.25 \%$, of the multiples. Two further questions beckon attention: Firstly, is it possible to further enhance the results obtained from this study by extending the proxy variables, especially in light of the emerging market challenges alluded to in Section 2, or will the emerging market context obscure a deeper analysis in this respect? Secondly, are the results obtained from this study methodology-specific, i.e. will the application of different methodologies yield different results?

An emerging market perspective: Although very few studies have been conducted on peer group selection in emerging markets, the topic has been covered in a number of studies in the developed market literature. Unfortunately, the scope of an investigation into an optimal peer group selection strategy in emerging markets is hamstrung by data limitations. Consider, for example, the evidence from this study, which suggests that multiples whose peer group selection is based on a combination of valuation fundamentals produce more accurate valuations than multiples whose peer group selection is based on single valuation fundamentals or industry classification. By implication, South African analysts should therefore employ a combination of valuation fundamentals for peer group selection purposes when employing multiples to perform equity valuations. The evidence also suggests that analysts should take cognisance of the substantial precision gains offered by RoE.TA and RoE.Rg, the latter in particular. Based on these results, one could envisage that a peer group selection strategy based on a triple combination of proxies for growth, profitability and risk, for example, would secure a further refinement in valuation precision. Therefore, the construction of multiples based on a combination of all three single valuation fundamentals, namely RoE. TA. Rg, was also tested, but due to the limited depth of the South African market, the number of peer groups produced by a triple combination was negligible. Consequently, the combination RoE. TA. Rg was excluded from this analysis.

Despite this limitation, the research results of this study concur with evidence from the developed capital markets regarding peer group selection. The empirical evidence from the developed market literature indicates that multiples whose peer groups are based on a combination of valuation fundamentals, particularly a combination of profitability and risk or a combination of profitability and growth, yield the most accurate equity valuations. It is of interest to note that the concurrence of the South African results with that of the developed market literature is independent of the methodology applied. As alluded to in Section 2, authors who applied different methodologies to the one applied in this study, obtained similar results (Henschke \& Homburg, 2009; Schreiner, 2007; Bhojraj \& Lee, 2002). However, the allure of the methodology employed in this study is that, unlike most theoretical models that are based on simplified realities, it is a realistic, if not near exact, reflection of how multiples are applied in practice. The latter is probably also the main reason that this approach has become so popular in the finance literature. It was introduced into the finance literature by Alford (1992), in a joint research effort between the Massachusetts Institute of Technology and corporate financiers from Ernst and Young and has subsequently been refined by various other scholars (Nissim, 2011; Minjina, 2008; Liu et al., 2007; 2002a; 2002b; Dittmann \& Weiner, 2005; Cheng \& McNamara, 2000; Gilson, Hotchkiss \& Ruback, 2000).

\section{Conclusion}

The primary aim of this paper was to establish whether there is an optimal basis for peer group selection. At its core, this entails a comparison of the valuation performance of multiples whose peer groups are based on industry classifications with multiples whose peer groups are based on valuation fundamentals. The evidence suggests that multiples whose peer groups are based on a combination of valuation fundamentals generally perform more accurate valuations than multiples whose peer groups are based on single valuation fundamentals or industry classifications. This holds true for $81.25 \%$ of the multiples tested in this study. The three multiples offering evidence to the contrary were NCIfIA, FCFE and FCFF. In other words, for $18.75 \%$ of the multiples tested, the evidence suggested that industry classification was the optimal basis for peer group selection. From these results it is evident that multiples whose peer groups are based on valuation fundamentals, particularly a combination of valuation fundamentals, dominate the valuation performance space in the South African market. The secondary aim was to establish which of the ten PGVs tested in this study, if any, offered the greatest degree of valuation precision. The evidence suggests that, for the $81.25 \%$ of the multiples tested in this study, the optimal 
choice of PGV is a combination of the valuation fundamentals Rg and RoE. The optimal choice of PGV for $12.50 \%$ of the multiples tested in this study was IND and for $6.25 \%$ of the multiples it was SUP. All 16 multiples that were tested in this study produced the least accurate valuations when their peer groups were based on single valuation fundamentals.

The third aim was to measure the magnitude of the potential improvement in valuation precision that an optimal choice of a PGV could potentially have on a sub-optimal choice of PGV. The research results suggests that the increase in valuation precision that could be secured by switching from sub-optimal PGVs to the optimal PGV could be as much as $41.77 \%$, which is substantial. As was the case with previous research, the evidence indicated that multiples whose peer groups are based on single valuation fundamentals produced the least accurate valuations for all 16 multiples, even less accurate than those multiples whose peer groups were based on industry classification. In general, multiples whose peer groups were based on industry classification produced more accurate valuations compared to those whose peer groups were based on single valuation fundamentals, but less so than multiples whose peer groups were based on a combination of valuation fundamentals, RoE.Rg and RoE.TA in particular. Therefore, the superior valuation performance of multiples whose peer groups are based on a combination of valuation fundamentals, RoE.Rg in particular, as deduced from the cross-sectional analysis conducted in previous studies, seems to hold when compared to those multiples whose peer group selection was based on industry classification.

The research results therefore presented empirical evidence in favour of the use of a combination of valuation fundamentals, rather than industry classification, as a basis for peer group selection. Equally evident was that the superior valuation performance of multiples whose peer groups were based on a combination of valuation fundamentals does not apply to all multiples, i.e. each multiple should be considered in isolation. However, investment practitioners should perhaps also consider more carefully their choice of PGV, since this may enable them to secure precision gains of up to $41.77 \%$. The following implications can be gleaned from these findings: Firstly, the results offer a comparative synopsis between the two schools of thought on peer group selection. As such, it offers a best practice guideline to analysts in emerging markets for peer group selection purposes. This is particularly helpful in emerging markets where there is limited empirical evidence on peer group selection and where failure to agree on valuations is cited as the main reason that transactions in emerging markets are not finalised.

Secondly, the proper construction of multiples requires a careful consideration of analysts' peer group selection strategies on an inter-school of thought basis and on an intra-school of thought basis. It was evident that neither of the two schools of thought on peer group selection produced the most accurate valuations among all 16 multiples that were investigated in this study. Therefore, peer group selection should not be based on a particular school of thought, but rather on a specific PGV on a case-by-case basis, regardless of the school of thought that the PGV represents. Generally, on an inter-school of thought basis, analysts should employ a peer group selection strategy that is based on valuation fundamentals, rather than a strategy that is based on industry classification. However, analysts should also guard against adopting a carte blanche approach to peer group selection that is based solely on a combination of valuation fundamentals. The latter observation seems particularly apt when employing the cash flowbased multiples NCIfIA. FCFE and FCFF, where a peer group selection strategy based on industry classification seems to present a more appropriate alternative. On an intra-school of thought basis, analysts should refrain from using single factor PGVs as a basis for peer group selection, since they generally produce the least accurate valuations. Thirdly, the evidence suggests that the valuation precision of multiples depends on the choice of PGV. Therefore, analysts should refrain from employing their favourite multiples before due consideration of their peer group selection strategy.

\section{References}

Alford, A. (1992). The effect of the set of comparable companies on the accuracy of the price-earnings valuation method. Journal of Accounting Research, 30, 94-108.

Asquith, P., Mikhail, M. B. \& Au, A. S. (2005). Information content of equity analyst reports. Journal of Financial Economics, 75, 245-282.

Barker, R. G. (1999). Survey and market-based evidence of sector-dependence in analysts' preferences between the dividend yield and price-earnings ratio valuation models. Journal of Business Finance and Accounting, 26(3\&4), 393-418. 
Beatty, R. P., Riffe, S. M. \& Thompson, R. (1999). The method of comparables and tax court valuations of private companies - An empirical investigation. Accounting Horizons, 13, 177-199.

Bhojraj, S. \& Lee, M. C. (2002). Who is my peer? A valuation-based approach to the selection of comparable companies. Journal of Accounting Research, 40, 407-439.

Cheng, C. S. A. \& McNamara, R. (2000). The valuation accuracy of the price-earnings and price-book benchmark valuation methods. Review of Quantitative Finance and Accounting, 15, 349-370.

Damodaran, A. (2009). The dark side of valuations, $2^{\text {nd }}$ edition, Pearson Education, Inc., New Jersey.

Damodaran, A. (2006a). Damodaran on valuation: security analysis for investment and corporate finance, $2^{\text {nd }}$ edition, John Wiley \& Sons, Inc., New Jersey.

Damodaran, A. (2006b). Valuation approaches and metrics: a survey of the theory and evidence, $2^{\text {nd }}$ edition, Now Publishers, Inc., Hanover.

Dellinger, R. (2010). Business valuation for the practitioner: Identifying the common area of manipulation by the valuator. The Florida Bar Journal, 84(8), 59-65.

Dittmann, I. \& Maug, E. (2008). Biases and error measures: How to compare valuation methods. Working paper. Rotterdam, Erasmus University, 1-38.

Dittmann, I. \& Weiner, C. (2005). Selecting comparable companies for the valuation of European firms, working paper, Erasmus University, Rotterdam.

Eberhart, A. C. (2001). Comparable firms and the precision of equity valuations. Journal of Banking and Finance, 25, 1367-1400.

Ernst, D. \& Hacker, J. (2012). Applied International Corporate Finance $2^{\text {nd }}$ edition. Franz Vahlen, München.

Fenn, G. W. \& Cole, R. A. (1994). Announcements of asset-quality problems and contagion effects in the life insurance industry. Journal of Financial Economics, 35, 181-198.

Fernández, P. (2001). Valuation using multiples. How do analysts reach their conclusions? Working paper. Madrid, IESE Business School, 1-13.

Fuller, R. J. \& Kerr, H. S. (1981). Estimating the divisional cost of capital: an analysis of the pure-play technique. Journal of Finance, 36, 997-1009.

Gilson, S. C., Hotchkiss, E. S. \& Ruback, R. S. (2000). Valuation of bankrupt firms. Review of Financial Studies, 13(70), 43-74.

Goedhart, M., Koller, T. \& Wessels, D. (2005). The right role for multiples in valuation. McKinsey on Finance, 15, 7-11.

Goedhart, M., Koller, T. \& Wessels, D. (2010). Valuation: Measuring and managing the value of companies. $5^{\text {th }}$ edition. John Wiley \& Sons, Ltd., New Jersey.

Gower, J., Lubbe, S. \& Le Roux, N. (2011). Understanding Biplots. $1^{\text {st }}$ edition. John Wiley \& Sons, Ltd., Chichester.

Henschke, S. \& Homburg, C. (2009). Equity valuation using multiples: controlling for differences between firms, Working paper, University of Cologne, Cologne.

Herrmann, V. \& Richter, F. (2003). Pricing with performance-controlled multiples. Schmalenbach Business Review, 55, 194-219.

International Monetary Fund (IMF). (2012). World Economic Outlook Database, World Economic and Financial Surveys, IMF, Washington.

Lang, L. H. P. \& Stulz, R. M. (1992). Contagion and competitive intra-industry effects of bankruptcy announcements: an empirical analysis. Journal of Financial Economics, 32, 45-60.

Liu, J., Nissim, D. \& Thomas, J. (2007). Is cash flow king in valuations? Financial Analysts Journal, 63(2), 113.

Liu, J., Nissim, D. \& Thomas, J. (2002a). Equity valuation using multiples. Journal of Accounting Research, $40(1), 135-172$.

Liu, J., Nissim, D. \& Thomas, J. (2002b). International equity valuation using multiples, Working paper, University of California at Los Angeles (Anderson Graduate School of Management), Los Angeles.

Minjina, D. I. (2008). Multiples and their use for equity valuation on European capital markets. Theoretical and Applied Economics, 11, 22-28.

Nel, W. S., Bruwer, B. W. \& Le Roux, N. J. (2014a).An emerging market perspective on peer group selection based on valuation fundamentals. Applied Financial Economics, 24(9), 621-637.

Nel, W. S., Bruwer, B. W. \& Le Roux, N. J. (2014b). Precision, consistency and bias in emerging equity markets. Journal of Economic and Behavioral Studies, 6(5), 386-399.

Nel, W. S., Bruwer, B. W. \& Le Roux, N. J. (2014c). An emerging market perspective on key value drivers when valuing cross-border transactions into South Africa. Economics, Management and Financial Markets, 9(4), 92-111. 
Nel, W. S., Bruwer, B. W. \& Le Roux, N. J. (2013a). The impact of industry classification on the valuation accuracy of multiples in the South African capital market. International Business and Economics Research Journal, 12, 79-102.

Nel, W. S., Bruwer, B. W. \& Le Roux, N. J. (2013b). Equity- and company-based multiples in emerging markets: evidence from the JSE Securities Exchange. Journal of Applied Business Research, 13, 829-852.

Nel, W. S. (2010). A South African perspective on the multiples of choice in the valuation of ordinary shareholders' equity: from theory to practice. African Journal of Business Management, 4, 930941.

Nel, W. S. (2009a). The use of multiples in the South African equity market: is the popularity of the price earnings ratio justifiable from a sector perspective? Meditari Accountancy Research, 17, 101-115.

Nel, W. S. (2009b). Methods of choice in the valuation of ordinary shareholders' equity: evidence from theory and practice. Meditari Accountancy Research, 17(2), 117-135.

Nissim, D. (2011). Ratio analysis and equity valuation: Relative Valuation of U.S. Insurance Companies, Working paper, New York, Columbia University, 1-55.

Omran, M. F. (2003). Equity valuation using multiples in the emerging market of the United Arab Emirates. Review of Middle East Economics and Finance, 1, 267-283.

PricewaterhouseCoopers (PwC). (2012). An African perspective: valuation methodology survey, $6^{\text {th }}$ edition, Johannesburg.

PricewaterhouseCoopers (PwC). (2010). Valuation Methodology Survey. [Online]. Available at http: //www.pwc.com. Accessed: 5 January 2015.

Profile (2011). Profile's Stock Exchange Handbook, Profile Media, Johannesburg.

R Core Team (2014). R: A language and environment for statistical computing. R Foundation for Statistical Computing, Vienna, Austria. URL: http://www.R-project.org/.

Roosenboom, P. (2007). How Do Underwriters Value Initial Public Offerings? An Empirical Analysis of the French IPO Market. Contemporary Accounting Research, 24, 1217-1243.

Schreiner, A. (2007). Equity valuations using multiples: an empirical investigation, PhD dissertation, University of St Gallen, Austria.

Schreiner, A. \& Spremann, K. (2007). Multiples and their valuation accuracy in European equity markets, Working paper, University of Saint Gallen, Frankfurt.

Sehgal, S. \& Pandey, A. (2009). The behavior of price multiples in India (1990-2007). Asian Academy of Management Journal of Finance and Accounting, 5, 31-65.

World Federation of Exchanges (WFE). (2013). Statistics. [Online]. Available at http://www.worldexchanges.org. Accessed: 6February 2015. 